\title{
A Mindsponge-based view on the anti-vax attitude
}

\author{
Tam-Tri Le \\ Centre for Interdisciplinary Social Research \\ Phenikaa University, Hanoi, Vietnam \\ Written in Ho Chi Minh City on 17 October 2021
}

\begin{abstract}
Almost two years after the COVID-19 pandemic began, there are still (a considerable number of) people denying the health risk of the disease, despite the available statistics and scientific information. And recently while many low- and middle-income countries are still struggling to get sufficient vaccine supply for their people, certain groups in some developed countries actively protested against vaccination programs from their governments (Casilli \& Semeraro, 2021; Lu, 2021). Russia - a country that authorized COVID-19 vaccines very early - has been having a lot of difficulties with people's distrust issues toward vaccination, and the nation has reached record daily death numbers coming into this winter (Reuters, 2021). The anti-vax attitude (and "sciencedenying" in general) is not unique to this pandemic, but during such a global crisis, we can clearly see that besides knowledge and technology, the psychological aspect is crucial in driving collective perceptions and behaviors.
\end{abstract}

Here I will briefly address some theoretical points related to the whole anti-vax situation in terms of information processing without going into detailed analysis or examples (which would require careful formal investigations). This is based on the Mindsponge framework, which since its original proposal (Q. H. Vuong, 2016; Q. H. Vuong \& Napier, 2015) has been expanded in particular with a focus on the functions of trust within the information processing mechanism (Nguyen et al., 2021; Q.-H. Vuong et al., 2021). Some anti-vax-related phenomena or characteristics are presented as follows.

- Even when high-quality information is widely accessible, distrust ("negative priority pass") toward the sources (e.g. government's official statements, healthcare workers, mass media platforms, etc.) can decrease the perceived value of all information coming from those sources, and thus may lead to hasty rejection and poor reception of information.

- When misinformation has already been integrated into one's mindset, such values will be used as references when evaluating (filtering) new information. Opposing values (in this case, correct information) will be perceived as carrying higher costs (for being against the existing trusted values), and thus acceptance probability is decreased.

- People having the same misperception can reinforce each other on that misperception through communication. Groups such as anti-vax social media communities or local protests are some examples of the social environments that reinforce the values of established anti-vax ideas.

- The assessment that leads to whether accepting or rejecting a certain idea is highly subjective, which is why providing facts is not efficient in persuading anti-vax believers. A piece of information is only considered objective (as a fact) if it is perceived so (as a belief). 
- Politicalizing false beliefs about vaccination will add more attached values to such ideas and further reinforce that direction of evaluation (e.g. by linking the concepts of maskwearing and authoritarianism or vaccination and mind-control conspiracy). This is how the situation of misinformation can be exploited and turned into extremism (for whatever underlying motives).

- Deliberate misinformation spreaders can use the approach of "half-truth": citing and misinterpret scientific results as a foundation before throwing in baseless claims. This strategy first creates trust in listeners which may lead to hasty favoring subsequent related information without careful evaluation (Note how many conspiracy theorists often cite famous sources or events before blend in their own interpretations and theories).

\section{References}

Casilli, R., \& Semeraro, G. (2021, October 9). Anti-vax protesters in Rome target Draghi's office, union's headquarters. Reuters. https://www.reuters.com/world/europe/italian-police-use-water-cannonpush-back-anti-vax-protesters-rome-2021-10-09/

Lu, D. (2021, October 2). Victoria Covid vaccine mandate: Unions welcome move as protesters clash with police in Melbourne. The Guardian. https://www.theguardian.com/australia-

news/2021/oct/02/victoria-covid-vaccine-mandate-unions-welcome-move-as-protesters-clashwith-police-in-melbourne

Nguyen, M.-H., Le, T.-T., Nguyen, H.-K. T., Ho, M.-T., Nguyen, H. T. T., \& Vuong, Q.-H. (2021). Alice in Suicideland: Exploring the Suicidal Ideation Mechanism through the Sense of Connectedness and Help-Seeking Behaviors. International Journal of Environmental Research and Public Health, 18(7), 3681. https://doi.org/10.3390/ijerph18073681

Reuters. (2021, October 16). Russia's daily COVID-19 death toll at record high as vaccination program stalls. Reuters. https://www.reuters.com/world/russias-daily-covid-19-deaths-exceed-onethousand-mark-2021-10-16/

Vuong, Q. H. (2016). Global Mindset as the Integration of Emerging Socio-Cultural Values Through Mindsponge Processes: A Transition Economy Perspective. In J. Kuada (Ed.), Global Mindsets: Exploration and Perspectives (pp. 109-126). Routledge. https://doi.org/10.4324/97813157363968

Vuong, Q. H., \& Napier, N. K. (2015). Acculturation and global mindsponge: An emerging market perspective. International Journal of Intercultural Relations, 49, 354-367. https://doi.org/10.1016/j.jintrel.2015.06.003

Vuong, Q.-H., Nguyen, M.-H., \& Le, T.-T. (2021). A Mindsponge-Based Investigation into the PsychoReligious Mechanism Behind Suicide Attacks. Sciendo. https://doi.org/10.2478/9788366675599 